\title{
Ninjurin1 regulates lipopolysaccharide-induced inflammation through direct binding
}

\author{
MIN WOOK SHIN ${ }^{1}$, SUNG-JIN BAE ${ }^{1}$, HEE-JUN WEE ${ }^{1}$, HYO-JONG LEE $^{2}$, BUM JU AHN ${ }^{1,3}$, HOANG LE $^{1}$, \\ EUN JI LEE ${ }^{1}$, RAN HEE KIM ${ }^{1}$, HYE SHIN LEE ${ }^{1}$, JI HAE SEO ${ }^{1}$, JI-HYEON PARK ${ }^{1}$ and KYU-WON KIM ${ }^{1,4,5}$ \\ ${ }^{1}$ SNU-Harvard NeuroVascular Protection Research Center, College of Pharmacy and \\ Research Institute of Pharmaceutical Sciences, Seoul National University, Seoul 151-742; \\ ${ }^{2}$ College of Pharmacy, Inje University, Gimhae, Gyugnam 621-749, Republic of Korea; \\ ${ }^{3}$ Neuroprotection Research Laboratory, Departments of Radiology and Neurology, \\ Massachusetts General Hospital and Harvard Medical School, Charlestown, MA 02129, USA; \\ ${ }^{4}$ Department of Molecular Medicine and Biopharmaceutical Sciences, Graduate School of \\ Convergence Science and Technology, Seoul National University, Seoul 151-742; \\ ${ }^{5}$ Crop Biotechnology Institute, GreenBio Science and Technology, \\ Seoul National University, Pyeongchang 25354, Republic of Korea
}

Received August 17, 2015; Accepted November 23, 2015

DOI: 10.3892/ijo.2015.3296

\begin{abstract}
Ninjurin1 is a transmembrane protein involved in macrophage migration and adhesion during inflammation. It was recently reported that repression of Ninjurin1 attenuated the lipopolysaccharide (LPS)-induced inflammatory response in macrophages; however, the precise mechanism by which Ninjurin1 modulates LPS-induced inflammation remains poorly understood. In the present study, we found that the interaction between Ninjurin1 and LPS contributed to the LPS-induced inflammatory response. Notably, pull-down assays using lysates from HEK293T cells transfected with human or mouse Ninjurin1 and biotinylated LPS (LPS-biotin) showed that LPS directly bound Ninjurin1. Subsequently, LPS binding assays with various truncated forms of Ninjurin1 protein revealed that amino acids (aa) 81-100 of Ninjurin1 were required for LPS binding. In addition, knockdown experiments using Ninjl siRNA resulted in decreased nitric oxide (NO) and tumor necrosis factor- $\alpha$ (TNF $\alpha$ ) secretion upon LPS treatment in Raw264.7 cells. Collectively, our results suggest that Ninjurin1 regulates the LPS-induced inflammatory response through its direct binding to LPS, thus, identifying Ninjurin1 as a putative target for the treatment of inflammatory diseases, such as sepsis and inflammation-associated carcinogenesis.
\end{abstract}

Correspondence to: Dr Kyu-Won Kim, SNU-Harvard NeuroVascular Protection Research Center, College of Pharmacy and Research Institute of Pharmaceutical Sciences, Seoul National University, Seoul 151-742, Republic of Korea

E-mail: qwonkim@snu.ac.kr

Key words: ninjurin1, lipopolysaccharide, lipopolysaccharide binding, inflammation, macrophage

\section{Introduction}

Inflammation is involved with diverse pathological processes, including infection, diabetes, atherosclerosis, neurodegenerative disease, and cancer (1). In particular, inflammation plays a critical role in either inhibiting or promoting tumor progression, depending on the context, such as the stage and origin of the cancer. Inflammatory cells were initially thought to actively target tumor cells (2); however, recent research suggests that cancer could be provoked by the signaling crosstalk that occurs between inflammatory cells and tumor cells $(3,4)$. For example, tumor-associated macrophages that express cathepsins $\mathrm{B}$ and $\mathrm{S}$ are known to promote cancer growth and invasion in a pancreatic tumor model (5). Therefore, further investigation of the connection between inflammation and cancer is important for a better understanding of tumor pathology and developing improved tumor-directed therapeutics.

Bacterial infection is a major cause of inflammation and is mediated by a variety of bacterial cell compartments (6). LPS in the outer membrane is a principal pathogenic molecule in the case of gram-negative bacteria, whereas plasma membrane lipoprotein plays a similar role in mycoplasma, which lacks a cell wall and outer membrane (7). Both LPS and lipoprotein contain lipid moieties, lipid A and a lipoylated amino-terminal cysteinyl residue, respectively, that are responsible for stimulating the host immune response $(7,8)$. Ag 243-5 lipoprotein, originally isolated from Mycoplasma arginini, but also described as the P47 lipoprotein of $M$. hyorhinis, is reported to have a metastasis-promoting activity $(9,10)$. Interestingly, Ag 243-5 shows significant sequence homology with macrophage-activating lipoprotein-404 (MALP-404) from M.fermentans, which is known to increase cytokine production in human monocytes (11).

Several LPS binding molecules facilitate the biological effect of LPS on host cells. For instance, LPS-binding protein 
(LBP) binds aggregated LPS and then delivers monomeric LPS to CD14 (12). Membrane anchored protein CD14 functions as a critical toll-like receptor 4 (TLR4) co-receptor, and transfers LPS to the myeloid differentiation factor 2 (MD2)-TLR4 complex (13). Finally, LPS triggers the dimerization of TLR4, which subsequently initiates intracellular signaling cascades $(14,15)$. Besides, several other proteins are reported to bind LPS, including high mobility group box 1 protein (HMGB1) (16), CXCR4 (17), and $\beta_{2}$-glycoprotein I (18). These proteins are actively studied as inflammatory regulators and therapeutic candidates in inflammatory diseases, but the current data are not sufficient to address any meaningful applications.

Ninjurin1 was originally identified as an upregulated protein in injured nerves and is comprised of two transmembrane domains (aa 72-100 and aa 118-139), N-terminal (aa 1-71) and C-terminal (aa 140-152) extracellular domains, and cytosolic region (aa 101-117) (19). Our group and others have reported on the various roles of Ninjurin1 in macrophages, such as increasing adhesion to endothelial cells and motility during early ocular development and experimental autoimmune encephalomyelitis $(20,21)$. Moreover, it was recently revealed that Ninjurin1 modulates the TLR4-dependent inflammatory response triggered by LPS via p38 phosphorylation and activator protein-1 (AP-1) activation (22); however, the precise mechanism of its roles in the inflammatory response is enigmatic. In this study, we report that Ninjurin1 mediates LPS-induced inflammation by directly binding to LPS. This identification of Ninjurin1 and LPS binding likely provides an important insight into the regulation of macrophage-mediated inflammatory response and diseases.

\section{Materials and methods}

Cell culture. HEK293T and Raw264.7 cells were obtained from the American Type Culture Collection (ATCC, Manassas, VA, USA) and the Korean Cell Line Bank (KCLB, Seoul, Korea), respectively. Cells were cultured in Dulbecco's modified Eagle's medium (DMEM, GenDEPOT, Barker, TX, USA) supplemented with $10 \%$ fetal bovine serum (FBS, GenDEPOT), and $100 \mathrm{U} / \mathrm{ml}$ penicillin and $100 \mu \mathrm{g} / \mathrm{ml}$ streptomycin (GenDEPOT) at $37^{\circ} \mathrm{C}$ in a humidified $5 \% \mathrm{CO}_{2}$ atmosphere.

Construction of expression plasmids and transfection. Expression plasmids for human (NM_004148) and mouse (NM_013610) Ninjurin1 were constructed as described previously (21). To construct expression plasmids for N-terminal MYC-tagged human and mouse Ninjurin1, cDNA were amplified by PCR and subcloned into $\mathrm{pCS} 2^{+}-\mathrm{Myc}$. Truncated forms of mouse Ninjurin1, MYC-mNINJ1 (1-71), MYC-mNINJ1 (72-152), MYC-mNINJ1 (1-100), MYC-mNINJ1 (1-90), MYC-mNINJ1 (1-80), MYC-mNINJ1 (81-152), MYC-mNINJ1 (91-152), MYC-mNINJ1 (101-152), and MYC-mNINJ1 (71-110) plasmids were also constructed using $\mathrm{pCS} 2^{+}-\mathrm{Myc}$ as backbone. Designing and cloning of expression plasmid of non-tagged Ninjurin1 was described previously (23). Briefly, mouse Ninjurin1 cDNA was subcloned into pcDNA3.1 $1^{+}$myc/his backbone without removing a stop codon.

HEK293T cells at $3 \times 10^{6}$ cells/dish were cultured in $100-\mathrm{mm}$ culture dishes for $24 \mathrm{~h}$ and then expression plasmids were transfected using polyethylenimine (PEI, Sigma-Aldrich, St. Louis, MO, USA). After 48 h of culture, cells were washed with PBS and collected.

RNA interference. Ninjurin1 downregulation was performed with RNA interference. siNinj1 targeted to mouse Ninjurin1 was purchased from Life Technologies (Grand Island, NY, USA). Negative control of RNA interference, siControl with the scrambled sequence was purchased from Bioneer (Daejeon, Korea). The following sequences were used: siControl: 5'-CCTACGCCACCAAUUUCGUdTdT-3'; siNinj1: 5'-ACCGGCCCAUCAAUGUAAACCAUUA-3'. Raw264.7 cells at $2 \times 10^{5}$ cells/dish were cultured in $60-\mathrm{mm}$ culture dishes for $12 \mathrm{~h}$. siRNAs $(20 \mathrm{nM})$ were transfected using Lipofectamine RNAiMAX transfection reagent (Life Technologies). After $24 \mathrm{~h}$ of transfection, media were changed with presence or absence of $1 \mu \mathrm{g} / \mathrm{ml}$ LPS (Sigma-Aldrich). After another $24 \mathrm{~h}$, cultured supernatant and cells were collected.

Immunoblot analysis. Proteins were extracted in cell lysis buffer containing $50 \mathrm{mM}$ Tris- $\mathrm{Cl}(\mathrm{pH} \mathrm{7.4),} 300 \mathrm{mM}$ $\mathrm{NaCl}, 5 \mathrm{mM}$ EDTA, $0.02 \%(\mathrm{w} / \mathrm{v})$ sodium azide, $1 \%(\mathrm{w} / \mathrm{v})$ Triton X-100, $10 \mathrm{mM}$ iodoacetamide, $1 \mathrm{mM}$ phenylmethanesulfonyl fluoride, $2 \mu \mathrm{g} / \mathrm{ml}$ leupeptin, and protease inhibitor cocktail (Calbiochem, Billerica, MA, USA). Lysates were separated with SDS-PAGE and transferred to nitrocellulose membrane (GE Healthcare Life Sciences, Pittsburgh, PA, USA). The transferred membrane was probed with the specific antibodies. Antibodies to NOS2 purchased from BD Bioscience (San Diego, CA, USA), MYC and GAPDH from Santa Cruz Biotechnology (Dallas, TX, USA). Endogenous Ninjurin1 was detected by custom-made antibody that was raised in rabbit with aa 139-152 of mouse Ninjurin1 (Ninj1 $\left(\mathrm{b}_{139-152}\right)$ (23). Image was acquired using LAS3000 machine (GE Healthcare Life Sciences).

Immunoprecipitation and silver staining. Protein lysates $(1,000 \mu \mathrm{g})$ and $1 \mu \mathrm{g}$ of MYC antibody were incubated overnight at $4^{\circ} \mathrm{C}$ with gentle rotation. Protein A agarose (10 $\mu \mathrm{l}$ ) (EMD Millipore, Billerica, MA, USA) was added to each sample and the mixture was incubated at $4^{\circ} \mathrm{C}$ for $4 \mathrm{~h}$ with gentle rotation. After washing 5 times with washing buffer containing $50 \mathrm{mM}$ Tris-Cl (pH 7.4), $300 \mathrm{mM} \mathrm{NaCl,} 5 \mathrm{mM}$ EDTA, $0.02 \%$ (w/v) sodium azide, and $0.1 \%(\mathrm{w} / \mathrm{v})$ Triton $\mathrm{X}-100$, precipitated proteins were eluted by heating with SDS sample buffer at $95^{\circ} \mathrm{C}$ for $10 \mathrm{~min}$. Eluted sample was separated with SDS-PAGE followed by silver staining procedure using PlusOne Silver Staining kit (GE Healthcare Life Sciences) as recommended by the manufacturer.

Binding assay of Ninjurin1 with MALP-2. Macrophageactivating lipopeptide-2 (2 $\mu \mathrm{g})$ (MALP-2, Enzo Life Sciences, Farmingdale, NY, USA) was conjugated to NHS-activated agarose beads (Life Technologies) as recommended by the manufacturer. Protein lysates (500 $\mu \mathrm{g})$ and MALP-2 conjugated beads were incubated overnight at $4{ }^{\circ} \mathrm{C}$ with gentle rotation. After washing 5 times with washing buffer, binding proteins were eluted by heating with SDS sample buffer at $95^{\circ} \mathrm{C}$ for $10 \mathrm{~min}$. Eluted samples were further analyzed by immunoblot analysis. 
Binding assay of Ninjurinl with LPS. Binding assays were performed by pull-down with streptavidin sepharose beads (GE Healthcare Life Science) or immunoprecipitation with MYC antibody. For pull-down with streptavidin sepharose beads, $500 \mu \mathrm{g}$ of protein lysates and $4 \mu \mathrm{g}$ of LPS-biotin (InvivoGen, San Diego, CA, USA) were incubated overnight at $4^{\circ} \mathrm{C}$ with gentle rotation. Streptavidin sepharose beads $(10 \mu \mathrm{l})$ were added to each sample and incubated at $4^{\circ} \mathrm{C}$ for $2 \mathrm{~h}$ with gentle rotation. After washing 5 times with washing buffer, the bound proteins were eluted by heating with SDS sample buffer at $95^{\circ} \mathrm{C}$ for $10 \mathrm{~min}$. The eluted samples were further analyzed by immunoblot analysis. In case of immunoprecipitation with MYC antibody, 1,000 $\mu \mathrm{g}$ of protein lysates, $1 \mu \mathrm{g}$ of MYC antibody, and $10 \mu \mathrm{l}$ of protein A agarose were incubated overnight at $4^{\circ} \mathrm{C}$ with gentle rotation, after which the unbound molecules were removed using 5 washes with washing buffer. Washed protein A agarose was eluted for silver staining or incubated with $10 \mu \mathrm{g}$ of LPS-biotin at $4^{\circ} \mathrm{C}$ for $4 \mathrm{~h}$. After washing 5 times with washing buffer, the bound molecules were eluted. Eluted samples were detected using streptavidin-HRP (Thermo Fisher Scientific, Waltham, MA, USA).

Mass spectrometry. Candidate protein bands excised from silver stained gels were destained with destaining solution consisted of $30 \mathrm{mM}$ potassium ferricyanide and $100 \mathrm{mM}$ sodium thiosulfate for $5 \mathrm{~min}$ and then incubated with $200 \mathrm{mM}$ ammonium bicarbonate for $20 \mathrm{~min}$. The gels were dehydrated with acetonitrile and dried in a vacuum centrifuge. The dried gels were rehydrated with $50 \mathrm{mM}$ ammonium bicarbonate containing $200 \mathrm{ng}$ trypsin (Promega, Madison, WI, USA) for $45 \mathrm{~min}$, replaced solution to $50 \mathrm{mM}$ ammonium bicarbonate, and incubated overnight at $37^{\circ} \mathrm{C}$. Digested peptide was purified using a desalting column (GE loader tip, Eppendorf, Hamburg, Germany). Each peptide sample was applied to ESI-Q-TOF MS/MS spectrometer (ABSciex, Framingham, MA, USA). The deduced peptide sequence after MS/MS were analyzed by MASCOT search engine (http://www.matrixscience.com) against Swiss-Prot and NCBI databases.

Nitric oxide (NO) assay. Raw264.7 cells were plated into $60-\mathrm{mm}$ culture dishes at $2 \times 10^{5}$ cells/dish for $12 \mathrm{~h}$ and then transfected with Ninjl or negative control siRNA. After $24 \mathrm{~h}$ of culture, media were changed with or without LPS $(1 \mu \mathrm{g} / \mathrm{ml})$. After incubation for $24 \mathrm{~h}$, the culture supernatant was collected and cells were removed by centrifugation at $500 \mathrm{~g}$ for $3 \mathrm{~min}$. Culture supernatant $(100 \mu \mathrm{l})$ was mixed with $100 \mu \mathrm{l}$ of Griess reagent (1:1 mixture of $1 \%$ sulfanilamide in $30 \%$ acetate and $0.1 \% \mathrm{~N}-1$-naphthylethylenediamine dihydrochloride in $60 \%$ acetate) at room temperature for $10 \mathrm{~min}$. The absorbance of the incubated samples was measured by using microplate reader at $540 \mathrm{~nm}$. A standard curve drawn with known concentrations of sodium nitrite was applied to calculate the concentration of nitrite, the stable end product of NO.

Measurement of TNF $\alpha$ secretion. Raw264.7 cells were cultured in 96-well culture plates at $1 \times 10^{4}$ cells/well for $12 \mathrm{~h}$. The Raw264.7 cells were transfected with Ninj1 or negative control siRNA for $24 \mathrm{~h}$ and then media was removed and replaced with $200 \mu \mathrm{l}$ of fresh media with or without LPS $(1 \mu \mathrm{g} / \mathrm{ml})$. After $24 \mathrm{~h}$ of incubation, the culture supernatant was collected. Amount of secreted TNF $\alpha$ was measured using Mouse TNF $\alpha$ ELISA MAX kit (BioLegend, San Diego, CA, USA) following the manufacturer's instructions.

Statistical analysis. The data are expressed as the mean \pm SD. Differences between groups were analyzed by the unpaired two-tailed Student's t-test. $\mathrm{P}<0.05$ denoted the presence of statistically significance.

\section{Results}

Ag 243-5 protein binds human and mouse Ninjurin1. At the start of this study, immunoprecipitation, gel separation, and mass spectrometry analysis were performed to identify novel Ninjurin1 binding partners. For this, HEK293T cells were transfected with MYC-tagged human Ninjurin1 (MYC-hNINJ1) or empty control (mock) plasmid. Total lysates from transfected HEK293T cells were immunoprecipitated with MYC antibody, separated by SDS-PAGE, and then stained with silver nitrate. Notably, we found a $\sim 47-\mathrm{kDa}$ protein that co-immunoprecipitated with $\sim 36 \mathrm{kDa}$ MYC-hNINJ1 protein, but was not observed in the control sample (Fig. 1). To examine whether this $\sim 47-\mathrm{kDa}$ protein bound mouse Ninjurin1, immunoprecipitations were repeated with lysates from HEK293T cells transfected with MYC-tagged mouse Ninjurin1 (MYC-mNINJ1). Significantly, both hNINJ1 and mNINJ1 were capable of pulling-down the $\sim 47-\mathrm{kDa}$ protein (Fig. 1). As a control, MYC-h/mNINJ1 expression was confirmed by immunoblot analysis with MYC antibody (Fig. 1).

The $\sim 47-\mathrm{kDa}$ band was excised and analyzed by mass spectrometry in order to identify the protein of interest. The resulting ESI-MS spectrum presented with $\mathrm{m} / \mathrm{z}$ peaks ranging from 750 to 850 (Fig. 2A). The peak at $793.9 \mathrm{~m} / \mathrm{z}$ was sequenced and identified as a 14-amino acid peptide (IFSPATVFFTSIEK) in further MS/MS analysis (Fig. 2B). Unexpectedly, queries in the Swiss-Prot and NCBI databases using the MASCOT search engine revealed that the peptide sequence was identical to aa 317-330 of Ag 243-5 (BAA04082) (Fig. 2C). To determine the reason for mycoplasma protein existence in our HEK293T cell lysates, we tested our cultures for mycoplasma and found that the HEK293T cells used in the analysis were positive for contamination. Subsequent analyses revealed that non-contaminated HEK293T cell lysates did not contain this 47-kDa protein band (data not shown). Although unexpected, these observations were intriguing since several previous reports demonstrated a role for Ninjurin1 in the inflammatory response, but the precise mechanism was unknown. Thus, we hypothesized that Ninjurin1 could recognize microbial pathogens conjugated with lipid moieties, such as mycoplasma lipopeptide MALP-2, the MALP-404 N-terminus, and LPS.

MALP-2 and LPS bind human and mouse Ninjurin1. Both MALP-2 and LPS are bacterial endotoxins that induce inflammatory macrophage activation in a manner dependent on their lipid moieties. Therefore, we tested whether MALP-2 and LPS were also able to bind Ninjurin1 as observed with Ag 243-5. For this, MYC-h/mNINJ1 HEK293T cell lysates were incubated with MALP-2-conjugated beads, and the bound proteins were eluted and examined by immunoblot analysis. The same process was used for control samples with 

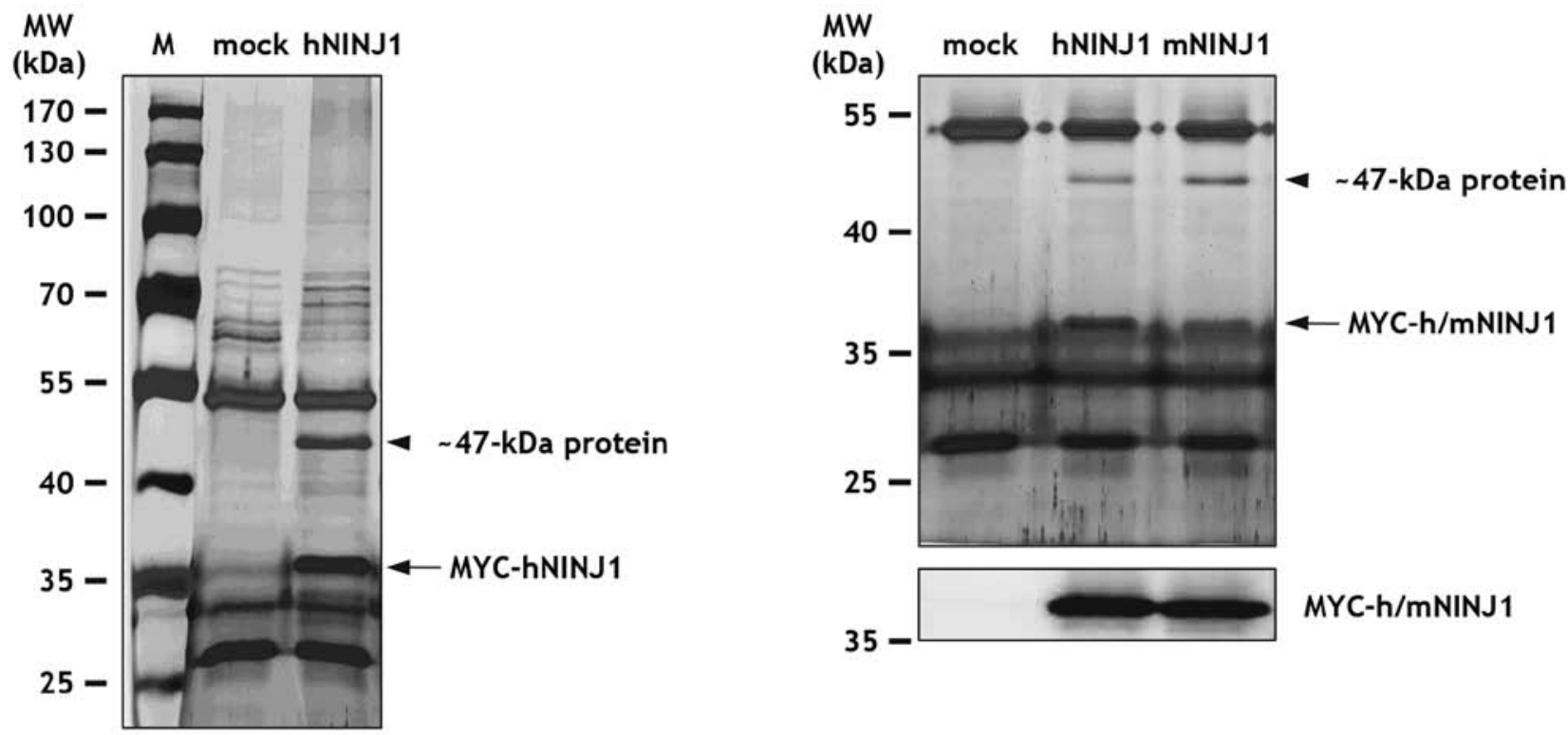

Figure 1. Binding of a $47-\mathrm{kDa}$ protein with Ninjurin1 in immunoprecipitation with MYC antibody. HEK293T cells were transfected with expression plasmid of MYC-tagged human or mouse Ninjurin1 (hNINJ1, mNINJ1) paralleling with empty control (mock) plasmid. Cell lysates $(1,000 \mu \mathrm{g})$ were immunoprecipitated using MYC antibody and agarose A beads. Precipitated protein was separated by SDS-PAGE and stained by silver nitrate. Arrow indicates MYC-h/ mNINJ1 and arrowhead indicates Ninjurin1 binding protein with $47-\mathrm{kDa}$ molecular weight. Expression of MYC-h/mNINJ1 was detected by immunoblot analysis with MYC antibody using $30 \mu \mathrm{g}$ of lysates (right lower). M, molecular-weight marker.

A

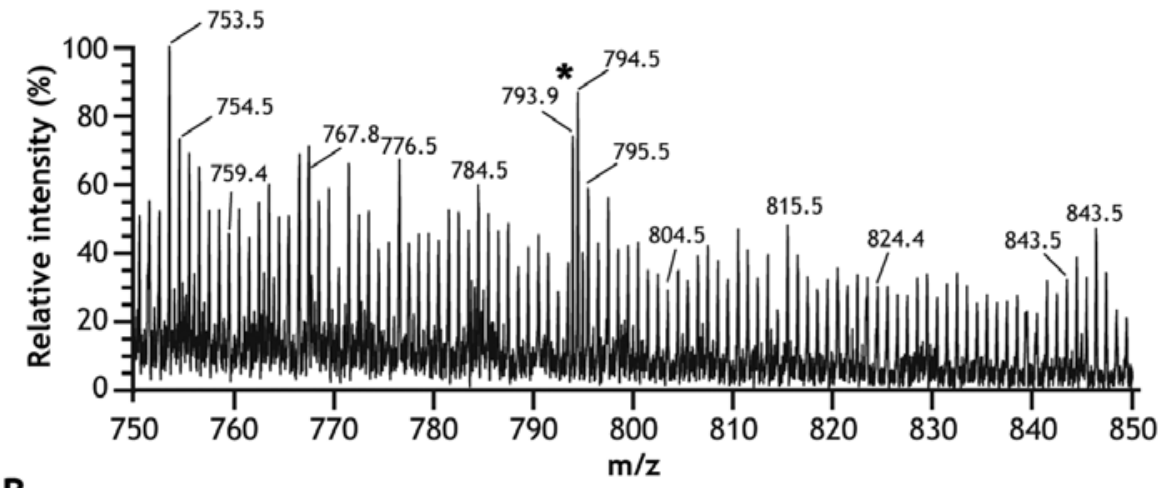

B

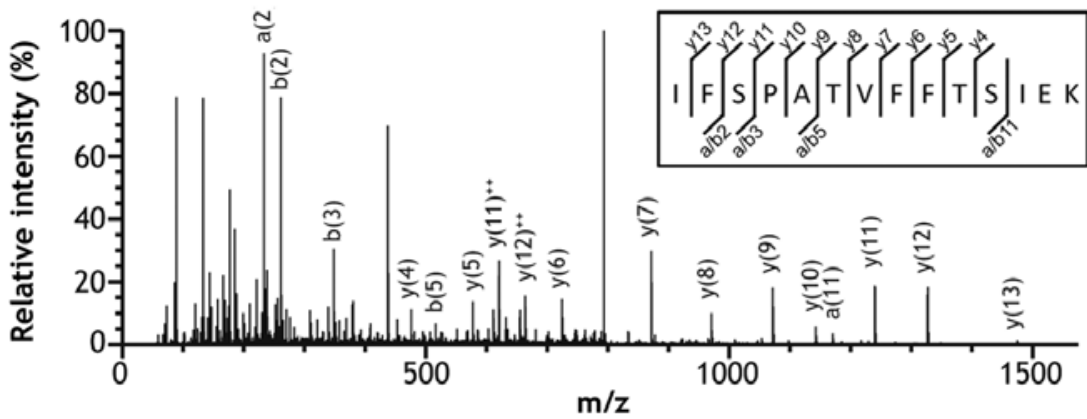

C

Ag 243-5 protein sequence

1 MNFKKSLLFLTGTISTVASV

21 ATFVSCGETDKEGKIIRIFD

41 NSFVKDRQAEIEKAKNFDFN

61 TVLLTAGGTVQDKSFNQSIW

81 EAVLEHYDQIEKTTNLDRVS

101 QETNNQSELIGKYKNFLNGN

121 KNVWILTGFQQGQEFPKFLK

141 QTDSNGKKYSDLLAEKKVII

161 VAVDWDLSKEDKDLIKAGHF

181 ISLLYKTEEAGFIAGYASSK

201 FLAYKFPNDEAKRTIAPFGG

221 GHGAGVTDFIAGFLAGIAKY

241 NNDNPTAKVTISDNNINIDT

261 GFISNDKTATFINGIVNKSS

281 LVLPVAGSLTSSVVDAIKKS

301 NKDTKYLIGVDTDQSKIFSP

321 ATVFFTSIEKHLGRTIYQVL

341 TDIWLKKEDSKFLGSFRSFK

361 LTNPANATVYKGISDDFVGV

381 SNSTVADADKVKAQEFLNEA

401 TADFKKQIQANPTNYKSVLG

421 IPTMLINDNDAKDNEKASLF

441 HFDNWQTYWAFHSRFIN

Figure 2. Identification of the $\sim 47-\mathrm{kDa}$ protein by ESI-MS/MS analysis. (A) ESI-MS spectrum of trypsin-digested of the $\sim 47-\mathrm{kDa}$ protein band. The peak at $793.9 \mathrm{~m} / \mathrm{z}$ (marked with asterisks) was subjected in further MS/MS analysis. (B) The MS/MS spectrum was identified as the partial tryptic peptide IFSPATVFFTSIEK. (C) Database searching with Swiss-Prot and NCBI protein databases. Peptide sequence (bold) was matched with aa 317-330 of Mycoplasma arginini protein Ag 243-5.

unconjugated beads. Results showed that human and mouse Ninjurin1 was efficiently pulled down with MALP-2 beads (Fig. 3A), but not control samples. In the case of LPS-biotin,
Ninjurin1-expressing cell lysates were incubated with or without LPS-biotin and streptavidin sepharose beads. Similar to that observed with MALP-2, human and mouse Ninjurin1 
A

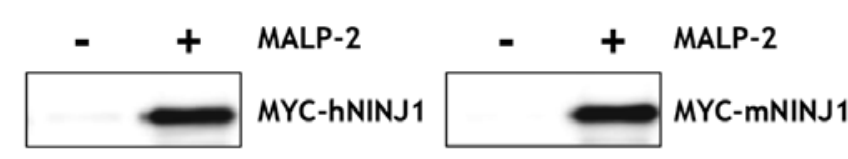

B

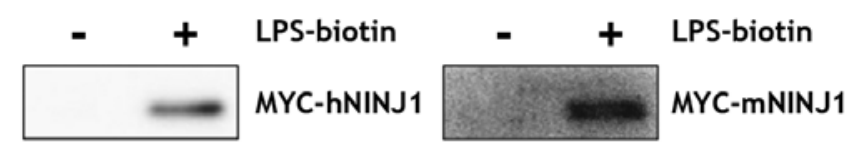

C

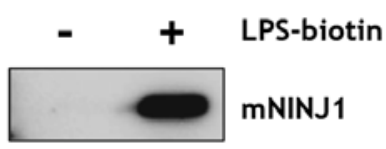

D
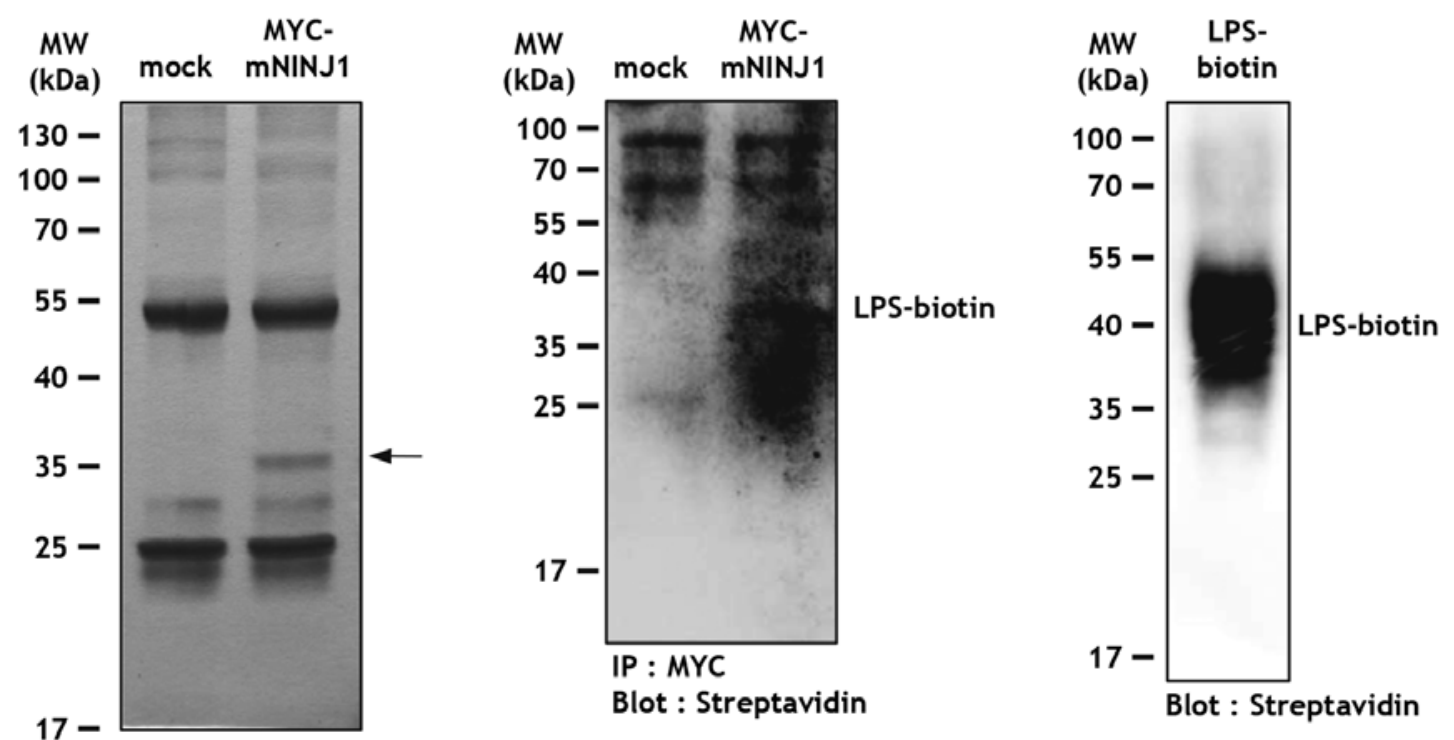

Figure 3. Binding assay between Ninjurin1 and LPS. MYC-h/mNINJ1 (A, B and D) or non-tagged mouse Ninjurin1 (C) was expressed in HEK293T cells. (A-C) Cell lysates $(500 \mu \mathrm{g})$ and mycoplasma lipoprotein macrophage-activating lipopeptide-2 (MALP-2, $2 \mu \mathrm{g}$ ) or biotinylated LPS (LPS-biotin, $4 \mu \mathrm{g}$ ) were mixed and pulled down by conjugating with beads or streptavidin beads, respectively. Binding of the Ninjurin1 protein to MALP-2 or LPS was detected with MYC (A and B) or Ninj1 $\mathrm{Ab}_{139-152}(\mathrm{C})$ antibodies. (D) Cell lysates $(1,000 \mu \mathrm{g})$ were immunoprecipitated with MYC antibody, the unbound proteins were washed away, and LPS-biotin $(10 \mu \mathrm{g})$ was then added. The protein was washed and immunoprecipitated, followed by staining with silver nitrate (left) and the binding of LPS to Ninjurin1 protein was detected using streptavidin-HRP (right). Arrow indicates MYC-mNINJ1.

were both able to bind LPS-biotin (Fig. 3B). To rule out the possibility of an interaction between the MYC peptide tag and LPS, LPS binding was assessed using lysates from HEK293T cells transfected with non-tagged mouse Ninjurin1 (mNINJ1) plasmid. As expected, non-tagged mouse Ninjurin1 also bound LPS-biotin (Fig. 3C). To exclude indirect binding through potential adaptor proteins, the unbound proteins were washed away from the immunoprecipitated MYC-mNINJ1 cell lysates, followed by addition of LPS-biotin. MYC-mNINJ1 protein was detected in the silver nitrate stained gel (Fig. 3D, arrow) and MYC-mNINJ1-bound LPS-biotin was detected by streptavidin-HRP, thus confirming a direct interaction between Ninjurin1 and LPS (Fig. 3D, right).

The a 81-100 region of Ninjurinl is responsible for LPS binding. To specify the region of Ninjurin1 responsible for LPS binding, truncated mouse Ninjurin1 expression plasmids were constructed. MYC-mNINJ1 (1-71) and MYC-mNINJ1 (72-152), encoding the extracellular N-terminal region and the two transmembrane, cytosolic, and extracellular C-terminus domains, respectively, were cloned into $\mathrm{pCS} 2^{+}-\mathrm{Myc}$ backbone plasmid. Full length MYC-mNINJ1, MYC-mNINJ1 (1-71), and MYC-mNINJ1 (72-152) were transfected to HEK293T cells and expression was confirmed by immunoblot analysis (Fig. 4A, lower). LPS binding assays were then performed using equal amounts of cell lysates and LPS-biotin (Fig. 4A, upper). Results showed that full-length MYC-mNINJ1 and MYC-mNINJ1 (72-152) bound LPS, whereas MYC-mNINJ1 (1-71) did not. To further delineate the binding region within Ninjurin1, additional expression plasmids of the truncated $\mathrm{N}$ - and C-terminals of mouse Ninjurin1 were constructed as follows: MYC-mNINJ1 (1-100), MYC-mNINJ1 (1-90), MYC-mNINJ1 (1-80), MYC-mNINJ1 (81-152), MYC-mNINJ1 (91-152), MYC-mNINJ1 (101-152), and MYC mNINJ1 (71-100). Ninjurin1 mutant expression was then examined by immunoblot analysis (Fig. 4B and 4C, lower). Notably, binding assays demonstrated that MYC-mNINJ1 (1-100), MYC-mNINJ1 (1-90), MYC-mNINJ1 (81-152), MYC-mNINJ1 (91-152), and MYC-mNINJ1 (71-110) bound 
A

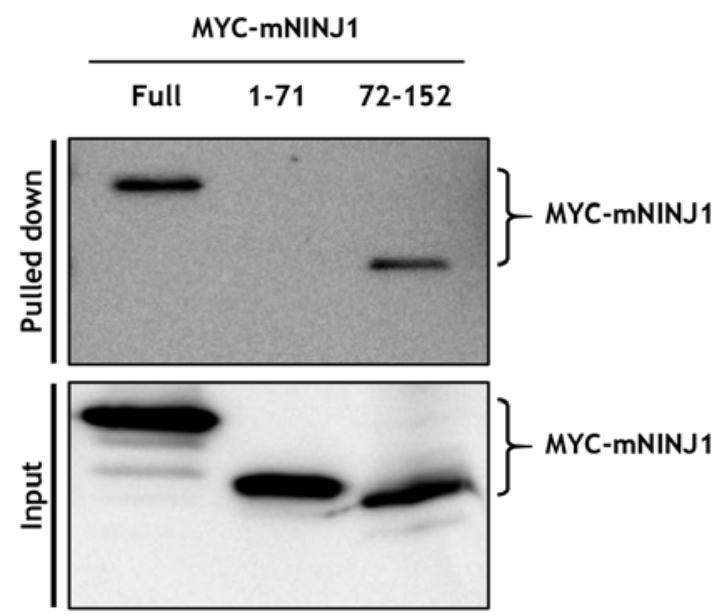

B

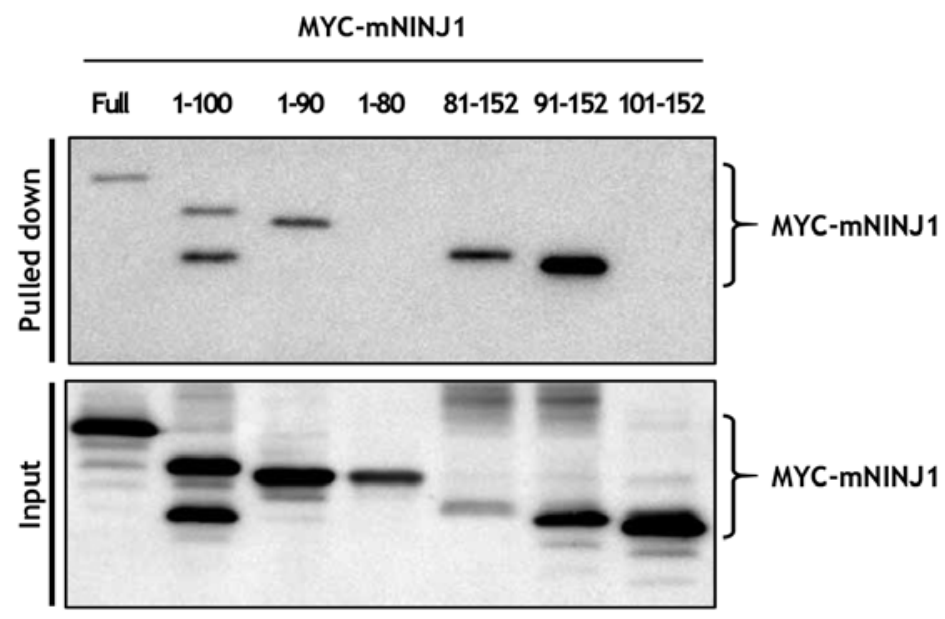

C

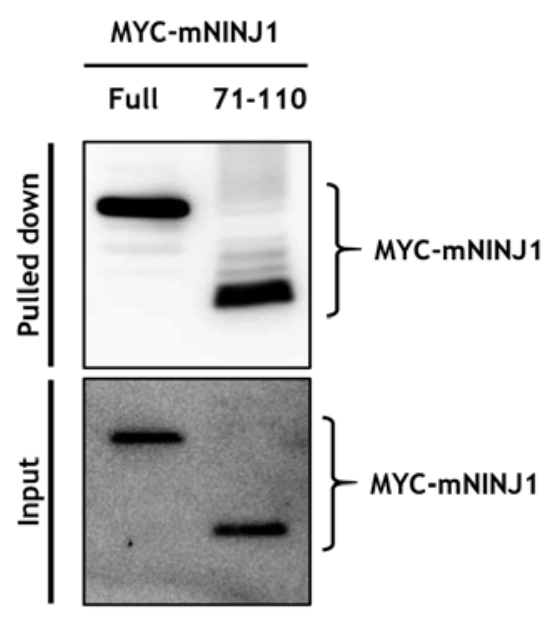

D

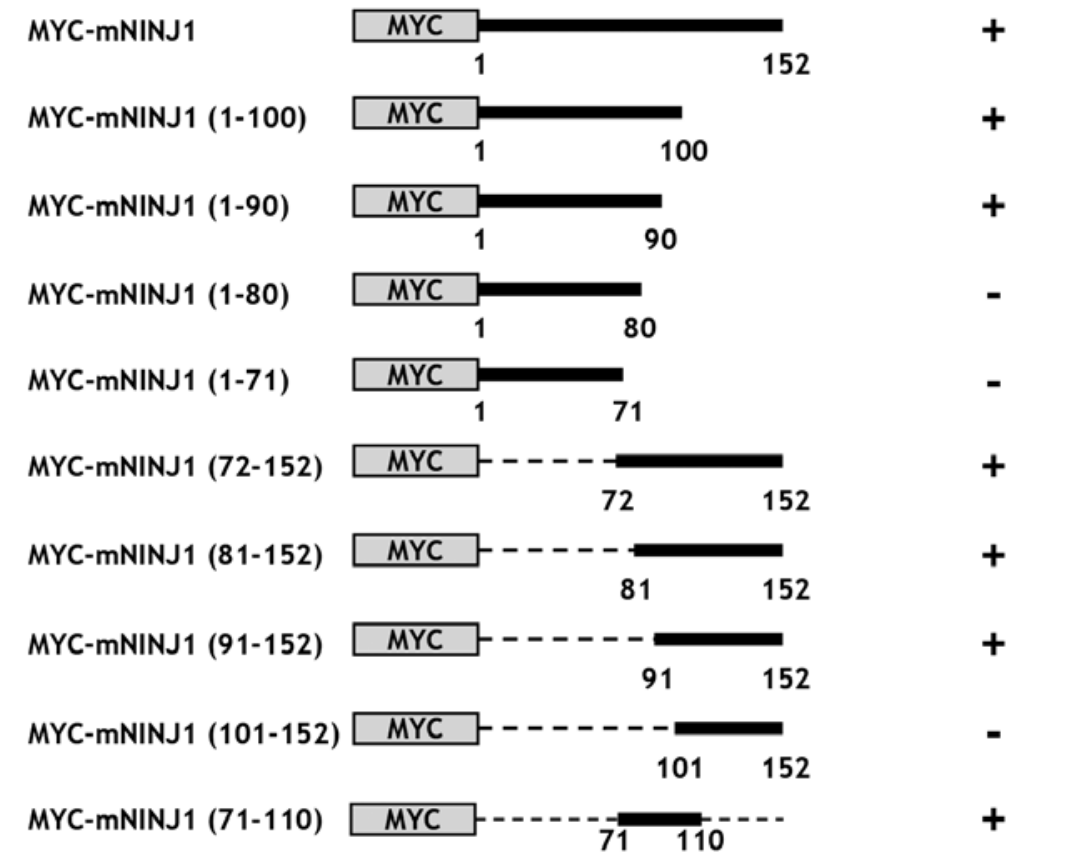

Figure 4. Determination of the LPS binding region of Ninjurin1. (A) Binding assay between LPS and MYC-mNINJ1 (1-71) or MYC-mNINJ1 (72-152). (B) Binding assay between LPS and MYC-mNINJ1 (1-100), MYC-mNINJ1 (1-90), MYC-mNINJ1 (1-80), MYC-mNINJ1 (81-152), MYC-mNINJ1 (91-152), and MYC-mNINJ1 (101-152). (C) Binding assay between LPS and MYC-mNINJ1 (71-110). Expression of transfected mNINJ1 constructs was detected by immunoblot analysis with MYC antibody (A-C, lower). Bindings between LPS and truncated Ninjurin1 were tested (A-C, upper). (D) A schematic diagram of MYC-tagged truncated mNINJ1 constructs.

LPS, whereas MYC-mNINJ1 (1-80) and MYC-mNINJ1 (101152) did not (Fig. 4B and C, upper). The binding abilities of these recombinant Ninjurin1 mutant proteins are summarized in Fig. 4D, and indicate that the aa 72-152 region of Ninjurin1 is required for LPS binding. Probably an aa 81-100 region of Ninjurin1 is essential for LPS binding, but it requires further experiments to define the essential region.

Ninjurin1 downregulation inhibits LPS-induced NO and $T N F \alpha$ secretion in Raw264.7 macrophages. Next, we inves- tigated the physiological basis of Ninjurin1 and LPS binding in the macrophage-mediated inflammatory response. Notably, LPS induced an increase of Ninjurin1 expression in Raw264.7 macrophages, consistent with a previous report (22). To elucidate the role of Ninjurin1 in the LPS-mediated inflammatory response, we silenced Ninjurin1 expression with specific or negative control siRNAs (siNinj1 and siControl, respectively) in Raw264.7 cells, and subsequently, analyzed the production of two well-known macrophage activation markers, NOS2 and $\mathrm{TNF} \alpha$. Interestingly, the induction of NOS2 protein expression 
A

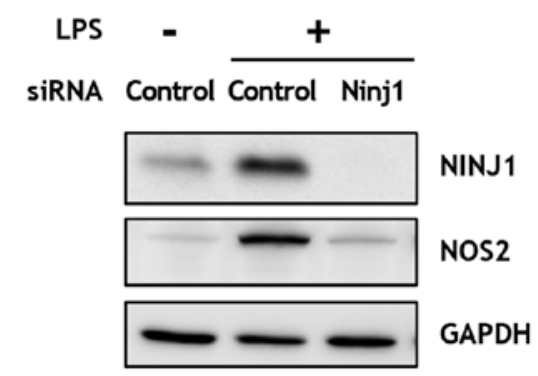

B

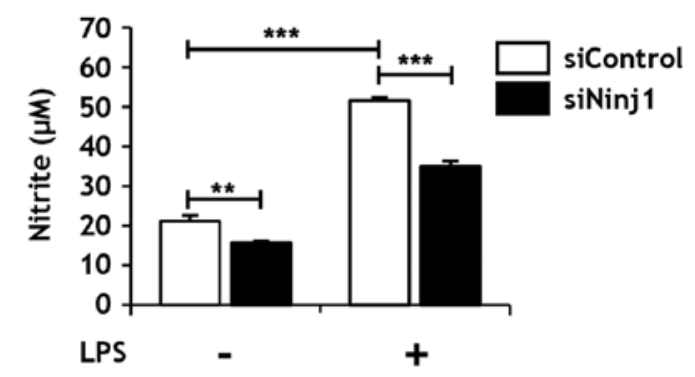

C

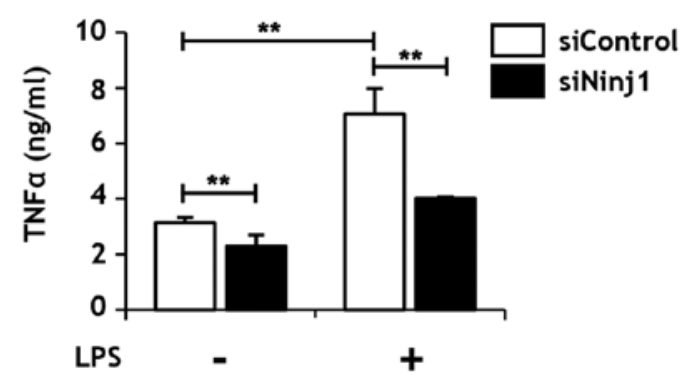

Figure 5. Effects of Ninjurin1 downregulation on LPS-induced Raw264.7 macrophage cell inflammation. The expression of Ninjurin1 was downregulated by transfecting Ninjurin1 targeted siRNA (siNinj1) or negative contro siRNA (siControl) in Raw264.7 cells. After $24 \mathrm{~h}$ of incubation, media were changed to with or without $1 \mu \mathrm{g} / \mathrm{ml}$ of LPS. Cell and conditioned media a $24 \mathrm{~h}$ were collected after LPS stimulation. (A) Protein lysates were analyzed by immunoblot analysis with Ninj1 $\mathrm{Ab}_{139-152}$, NOS2, and GAPDH antibodies. (B) NO release was determined using Griess reagent. Concentration of nitrite was calculated from sodium nitrite standard curve. (C) TNF $\alpha$ secretion was measured by ELISA assay. Conditioned media $(100 \mu 1)$ was applied to the assay. The data are mean $\pm \mathrm{SD} .{ }^{* *} \mathrm{p}<0.01,{ }^{* * * *} \mathrm{p}<0.001$.

by LPS treatment was inhibited in cells transfected siNinj1 (Fig. 5A), as was NO release (Fig. 5B). Similarly, TNF $\alpha$ secretion induced by LPS treatment was markedly inhibited in Ninjurin1-knockdown Raw264.7 cells (Fig. 5C). These results suggest that the LPS-induced inflammatory response was significantly inhibited by Ninjurin1-knockdown, likely due to the decreased direct interaction of Ninjurin1 and LPS.

\section{Discussion}

In this study, we identified Ninjurin1 as a novel LPS binding partner (Fig. 3). To determine the region of Ninjurin1 that conveyed its ability to bind LPS, binding assays were performed with Ninjurin1 mutant proteins. These results showed that LPS bound to Ninjurin1 aa 81-100, which belongs to first transmembrane domain (Fig. 4). Ninjurin1 has two transmembrane domains (aa 72-100 and 118-139), and both the regions are highly hydrophobic. In the binding assay using MYC-mNINJ1 (101-152), containing second transmembrane domain, LPS-biotin failed to bind to Ninjurin1 (Fig. 4B). Based on this observation, we proposed that LPS binds specifically to aa 81-100 of Ninjurin1. To address whether Ninjurin1-LPS binding affects cellular function, we repressed Ninjurin1 expression with siRNA in Raw264.7 cells. Notably, Ninjurin1 downregulation inhibited LPS-induced NOS2 enzyme induction, NO release, and TNF $\alpha$ secretion in Raw264.7 macrophages (Fig. 5), suggesting that the direct binding of LPS to Ninjurin1 was required for the inflammatory activation of macrophages by LPS.

The binding properties of Ninjurin1 were previously investigated mainly focussing on its homophilic binding domain $(20,24)$. In addition, a heterophilic interaction with unknown molecules has also been suggested based on results that the basal adhesion of wild-type Jurkat cells was inhibited by treatment with peptides containing Ninjurin1 adhesion motif (25). Moreover, Ninjurin1 overexpression led to enhanced macrophage adhesion to umbilical vein endothelial cells and extracellular matrix proteins, such as fibronectin, type I collagen, vitronectin, and type IV collagen $(21,26)$. In this study, we identified LPS as a novel heterophilic binding partner of Ninjurin1. Since the lipid moiety of LPS is crucial for its binding with Ninjurin1, it would be worthwhile to investigate the interaction between Ninjurin1 and other lipid-containing molecules.

Binding region of LPS-interacting partners would likely be a potent therapeutic target for inflammatory diseases. For example, synthetic peptides of the HMGB1 LPS-binding region, aa 3-15 or aa $80-96$, inhibits the interaction between LPS to HMGB1 in vitro, and also decreases TNFa production in a subclinical endotoxemia mouse model (27). Thus, we also sought to determine the region of Ninjurin1 responsible for LPS binding. It is already known that Ninjurin1 contains a homophilic binding domain (aa 26-37) important for its role in immune cell aggregation and macrophage-endothelial cell adhesion. Moreover, the aggregation of Ninjurin1expressing Jurkat cells is completely abolished by treatment with Ninjurin1 aa 26-37 peptide (25), and treatment with antibody directed towards this protein fragment blocks macrophage adhesion and transmigration to endothelial cells (20). Furthermore, LPS-induced $I L-6$ and $T N F \alpha$ transcription is inhibited by treatment with this aa 26-37 peptide (22); however, according to our result, LPS specifically bound aa 81-100 of Ninjurin1, but not the N-terminus containing the homophilic binding domain. This result indicates that Ninjurin1 harbors an LPS-binding motif separated from its homophilic binding domain. Therefore, identification of the specific LPS binding region in Ninjurin1 could be valuable for the precise regulation of LPS-induced inflammation, as it would presumably not affect the protein's role in cell adhesion.

Besides macrophages, Ninjurin1 is expressed in various cell types, such as endothelial cells, pericytes, fibroblasts, and epithelial cells $(26,28,29)$. Moreover, Ninjurin1 is implicated in several human diseases, including carcinogenesis of non-muscle-invasive urothelial bladder cancer (30) and hepa- 
tocellular carcinoma (31). Likewise, LPS also affects various cell types and pathological conditions, which are not only restricted to immune cells. For example, human endothelial cells treated with LPS produce neutrophil chemotactic factor (32), whereas LPS stimulation in mouse CT26 colon cancer cells triggers NF- $\kappa B-D N A$ binding (33).

Collectively, the Ninjurin1-LPS interaction would likely affect various cellular functions beyond macrophage inflammation. Thus, the Ninjurin1 LPS-binding domain would be an attractive therapeutic target for inflammatory diseases.

\section{Acknowledgements}

This study was supported by the Global Research Laboratory Program (2011-0021874), the Global Core Research Center (GCRC) Program (2011-0030001), the International Cooperation Program (2014K2A1C2074279), the Basic Science Research Program (2013R1A1A2058956) through the National Research Foundation (NRF) funded by the Korean Ministry of Science, ICT and Future Planning (MSIP).

\section{References}

1. Medzhitov R: Inflammation 2010: New adventures of an old flame. Cell 140: 771-776, 2010.

2. Urban JL, Shepard HM, Rothstein JL, Sugarman BJ and Schreiber H: Tumor necrosis factor: A potent effector molecule for tumor cell killing by activated macrophages. Proc Natl Acad Sci USA 83: 5233-5237, 1986.

3. Grivennikov SI, Greten FR and Karin M: Immunity, inflammation, and cancer. Cell 140: 883-899, 2010.

4. Coussens LM and Werb Z: Inflammation and cancer. Nature 420: $860-867,2002$

5. Gocheva V, Wang HW, Gadea BB, Shree T, Hunter KE, Garfall AL, Berman T and Joyce JA: IL-4 induces cathepsin protease activity in tumor-associated macrophages to promote cancer growth and invasion. Genes Dev 24: 241-255, 2010.

6. Akira S: Pathogen recognition by innate immunity and its signaling. Proc Jpn Acad, Ser B, Phys Biol Sci 85: 143-156, 2009.

7. Chambaud I, Wróblewski $\mathrm{H}$ and Blanchard A: Interactions between mycoplasma lipoproteins and the host immune system. Trends Microbiol 7: 493-499, 1999.

8. Beutler B and Rietschel ET: Innate immune sensing and its roots: The story of endotoxin. Nat Rev Immunol 3: 169-176, 2003.

9. Calcutt MJ, Kim MF, Karpas AB, Mühlradt PF and Wise KS: Differential posttranslational processing confers intraspecies variation of a major surface lipoprotein and a macrophageactivating lipopeptide of Mycoplasma fermentans. Infect Immun 67: 760-771, 1999.

10. Ushio S, Iwaki K, Taniai M, Ohta T, Fukuda S, Sugimura K and Kurimoto M: Metastasis-promoting activity of a novel molecule, Ag 243-5, derived from mycoplasma, and the complete nucleotide sequence. Microbiol Immunol 39: 393-400, 1995.

11. Rosati S, Pozzi S, Robino P, Montinaro B, Conti A, Fadda M and Pittau M: P48 major surface antigen of Mycoplasma agalactiae is homologous to a malp product of Mycoplasma fermentans and belongs to a selected family of bacterial lipoproteins. Infect Immun 67: 6213-6216, 1999.

12. Hailman E, Lichenstein HS, Wurfel MM, Miller DS, Johnson DA, Kelley M, Busse LA, Zukowski MM and Wright SD: Lipopolysaccharide (LPS)-binding protein accelerates the binding of LPS to CD14. J Exp Med 179: 269-277, 1994.

13. Wright SD, Ramos RA, Tobias PS, Ulevitch RJ and Mathison JC: CD14, a receptor for complexes of lipopolysaccharide (LPS) and LPS binding protein. Science 249: 1431-1433, 1990.

14. Jerala R: Structural biology of the LPS recognition. Int J Med Microbiol 297: 353-363, 2007.
15. Miyake K: Innate recognition of lipopolysaccharide by Toll-like receptor 4-MD-2. Trends Microbiol 12: 186-192, 2004.

16. Youn JH, Oh YJ, Kim ES, Choi JE and Shin JS: High mobility group box 1 protein binding to lipopolysaccharide facilitates transfer of lipopolysaccharide to CD14 and enhances lipopolysaccharide-mediated TNF-alpha production in human monocytes. J Immunol 180: 5067-5074, 2008.

17. Triantafilou K, Triantafilou M and Dedrick RL: A CD14independent LPS receptor cluster. Nat Immunol 2: 338-345, 2001.

18. Agar C, de Groot PG, Mörgelin M, Monk SD, van Os G, Levels JH, de Laat B, Urbanus RT, Herwald H, van der Poll T, et al: $\beta(2)$-glycoprotein I: A novel component of innate immunity. Blood 117: 6939-6947, 2011.

19. Araki T and Milbrandt J: Ninjurin, a novel adhesion molecule, is induced by nerve injury and promotes axonal growth. Neuron 17: 353-361, 1996.

20. Ahn BJ, Le H, Shin MW, Bae SJ, Lee EJ, Wee HJ, Cha JH, Lee HJ, Lee HS, Kim JH, et al: Ninjurin1 deficiency attenuates susceptibility of experimental autoimmune encephalomyelitis in mice. J Biol Chem 289: 3328-3338, 2014.

21. Lee HJ, Ahn BJ, Shin MW, Jeong JW, Kim JH and Kim KW: Ninjurin1 mediates macrophage-induced programmed cell death during early ocular development. Cell Death Differ 16: 1395-1407, 2009.

22. Jennewein C, Sowa R, Faber AC, Dildey M, von Knethen A, Meybohm P, Scheller B, Dröse S and Zacharowski K: Contribution of ninjurin1 to toll-like receptor 4 signaling and systemic inflammation. Am J Respir Cell Mol Biol 53: 656-663, 2015.

23. Ahn BJ, Le H, Shin MW, Bae SJ, Lee EJ, Wee HJ, Cha JH, Park JH, Lee HS, Lee HJ, et al: The N-terminal ectodomain of Ninjurin1 liberated by MMP9 has chemotactic activity. Biochem Biophys Res Commun 428: 438-444, 2012.

24. Ifergan I, Kebir H, Terouz S, Alvarez JI, Lécuyer MA, Gendron S, Bourbonnière L, Dunay IR, Bouthillier A, Moumdjian R, et al: Role of Ninjurin-1 in the migration of myeloid cells to central nervous system inflammatory lesions. Ann Neurol 70: 751-763, 2011.

25. Araki T, Zimonjic DB, Popescu NC and Milbrandt J: Mechanism of homophilic binding mediated by ninjurin, a novel widely expressed adhesion molecule. J Biol Chem 272: 21373-21380, 1997.

26. Lee HJ, Ahn BJ, Shin MW, Choi JH and Kim KW: Ninjurin1: A potential adhesion molecule and its role in inflammation and tissue remodeling. Mol Cells 29: 223-227, 2010.

27. Youn JH, Kwak MS, Wu J, Kim ES, Ji Y, Min HJ, Yoo JH, Choi JE, Cho HS and Shin JS: Identification of lipopolysaccharide-binding peptide regions within HMGB1 and their effects on subclinical endotoxemia in a mouse model. Eur J Immunol 41: 2753-2762, 2011.

28. Matsuki M, Kabara M, Saito Y, Shimamura K, Minoshima A, Nishimura M, Aonuma T, Takehara N, Hasebe N and Kawabe J: Ninjurin1 is a novel factor to regulate angiogenesis through the function of pericytes. Circ J 79: 1363-1371, 2015.

29. Cho SJ, Rossi A, Jung YS, Yan W, Liu G, Zhang J, Zhang M and Chen X: Ninjurin1, a target of p53, regulates p53 expression and p53-dependent cell survival, senescence, and radiation-induced mortality. Proc Natl Acad Sci USA 110: 9362-9367, 2013.

30. Mhawech-Fauceglia P, Ali L, Cheney RT, Groth J and Herrmann FR: Prognostic significance of neuron-associated protein expression in non-muscle-invasive urothelial bladder cancer. J Clin Pathol 62: 710-714, 2009.

31. Kim JW, Moon AR, Kim JH, Yoon SY, Oh GT, Choe YK and Choe IS: Up-regulation of ninjurin expression in human hepatocellular carcinoma associated with cirrhosis and chronic viral hepatitis. Mol Cells 11: 151-157, 2001.

32. Strieter RM, Kunkel SL, Showell HJ, Remick DG, Phan SH, Ward PA and Marks RM: Endothelial cell gene expression of a neutrophil chemotactic factor by TNF-alpha, LPS, and IL-1 beta. Science 243: 1467-1469, 1989.

33. Luo JL, Maeda S, Hsu LC, Yagita H and Karin M: Inhibition of NF-kappaB in cancer cells converts inflammation- induced tumor growth mediated by TNFalpha to TRAIL-mediated tumor regression. Cancer Cell 6: 297-305, 2004. 